\title{
Oxidation Influence on Water Solubility in Aviation Jet Fuel
}

\author{
Vladimir L. Zherebtsov*, Marina M. Peganova \\ RSC “Applied Chemistry”, Saint Petersburg, Russia \\ Email: ${ }^{\star}$ gevlaleo@mail.ru
}

How to cite this paper: Zherebtsov, V.L. and Peganova, M.M. (2017) Oxidation Influence on Water Solubility in Aviation Jet Fuel. Open Access Library Journal, 4: e3404. https://doi.org/10.4236/oalib.1103404

Received: January 24, 2017

Accepted: April 3, 2017

Published: April 6, 2017

Copyright (C) 2017 by authors and Open Access Library Inc.

This work is licensed under the Creative Commons Attribution International License (CC BY 4.0).

http://creativecommons.org/licenses/by/4.0/

\section{(c) (†) Open Access}

\begin{abstract}
The samples of naphthenic base hydrocarbon fuel (kerosene fraction) and the samples prepared on their basis at the similar conditions with different degrees of oxidation were investigated. Following the oxidation for each sample reacted with a certain amount of oxygen various physical and chemical parameters were determined. The studies showed a significant effect of natural surfactants on water solubility. The possibility of forming micellar colloidal structures in hydrocarbon fuels with increasing concentrations of natural surfactant-oxidation products was determined. The increase in water solubility can result from solubilization of the water molecules inside reverse micelles formed by the oxidation products of hydrocarbon fuels.
\end{abstract}

\section{Subject Areas}

Aerospace Engineering

\section{Keywords}

Water, Solubility, Aviation Fuel, Oxidation, Surfactants, Micells

\section{Introduction}

Saturated water solubility in hydrocarbon fuels can differ significantly [1], not only for different sorts of fuels, but also for a variety of different batches of fuels [2]. A strong influence on the solubility of water has a group hydrocarbon composition, in particular the content of aromatic hydrocarbons has a maximum solubility [3]. The fractional composition, additive content are also important. However, the value of these parameters for a specific fuel grade is definite, and tolerances within the normative documents do not have a noticeable effect on water solubility [4].

Given the differences in the history of production and storage of one grade 
fuels samples but different parties has been suggested the possibility of impact on the water solubility of various oxidation states, despite the fact that the standard documentation analysis of the main oxidation degree indicators, namely the "Existent gum" content and "Acidity" showed virtually no products of the liquid phase oxidation [5].

It has been suggested that surfactants that accumulate in the fuel during its oxidation have a decisive role for changing the equilibrium solubility limit of water in fuel and hence undissolved water content in aircraft fuel systems. Undissolved (free) water is a fuel contaminant which can starve engines if injected as a slug into the engine system. It can also freeze to form ice crystals capable of plugging fuel filters and can support microbiological contamination, contributing to the corrosion of metallic components [1] [2] [3].

\section{Experimental Part}

The samples of naphthenic base hydrocarbon fuel (kerosene fraction) and the samples prepared on their basis at the similar conditions with different degrees of oxidation were investigated.

Oxidation was carried out in the laboratory by bubbling air through the fuel bed at a temperature of $100^{\circ} \mathrm{C}$ (Figure 1). Main parameters of the experiment are:

Reactor-glass Liebig type column with heating jacket;

Fuel volume-1 litre;

Column height -1 meter;

Oxidation time-1 - 5 hours;

Heater thermostat circulator-Julabo FP40;

Heat transfer agent-glycerine;

Air consumption $-0.2 \mathrm{ml} / \mathrm{sec}$.
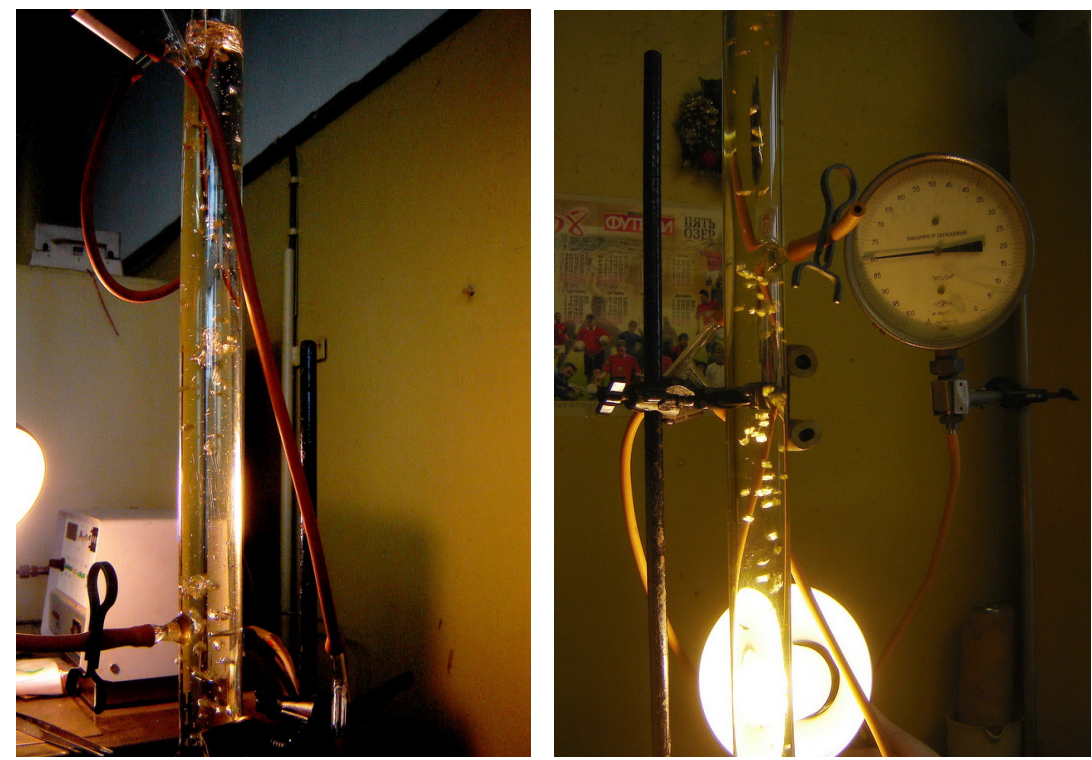

Figure 1. Laboratory rig for kerosene oxidation research. 
The air gas was bubbled in the fuel at the bottom of the fuel column via a single nozzle in a hollow needle.

Oxidation degree $\frac{\sum \Delta V o_{2}}{V_{f}}$ or the total amount of reacted oxygen $\sum \Delta V o_{2}$ divided by the fuel volume $V_{f}$ was determined by the results of the gas-liquid chromatography method analysis of the oxygen in liquid and gas phases. Chromatograph "3700" model (RF) was used.

Following the oxidation of the fuel for each sample reacted with a certain amount of oxygen various physical and chemical parameters were determined.

Surface tension $\sigma$ and the interfacial tension $\sigma_{i}$ were determined by the maximum bubble (drop) pressure of air (fuel) at $0.02 \mathrm{~mm}$ capillary diameter (Rebinder method).

Electro physical parameters (dielectric constant $\varepsilon$ and the dielectric loss tangent $\operatorname{tg} \delta$ ) were measured using the AC bridge R-589 and DT-CT converter designed in the RSC "Applied Chemistry" (TO 6-02-2-645-81).

Saturated water solubility $C_{\lim }^{\text {sat }}$ in a temperature range of plus $20^{\circ} \mathrm{C}$ to minus $40^{\circ} \mathrm{C}$ was determined by the $100 \%$ humidity creation in the volume above the fuel bed when mixing [1] [6]. The schematic of the laboratory rig is shown in Figure 2.

The limit dryness parameter $C_{\lim }^{\text {dry }}$ was defined as the amount of water remaining in the fuel after an hour drying under vacuum.

"Existent Gum" $G$ content was defined in accordance with GOST 8489-58 (RF).

"Acidity" $A$ was defined in accordance with GOST 5985-59(RF).

The content of dissolved water $C_{W}$ was determined by Karl Fisher coulometric titration method (GOST 24614-81).

Fuel samples infrared spectroscopy was conducted on IKS-29 spectrometer. All measurements were performed at room temperature.

\section{Results and Discussion}

Experimental data are represented in Figure 3 and Figure 4. It is shown that all

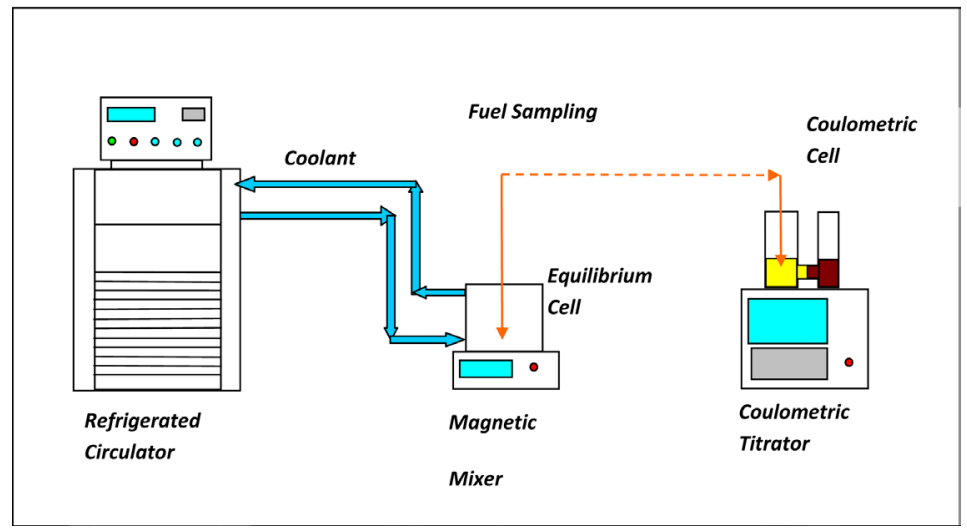

Figure 2. The schematic of the laboratory rig for water solubility in kerosene versus temperature research. 


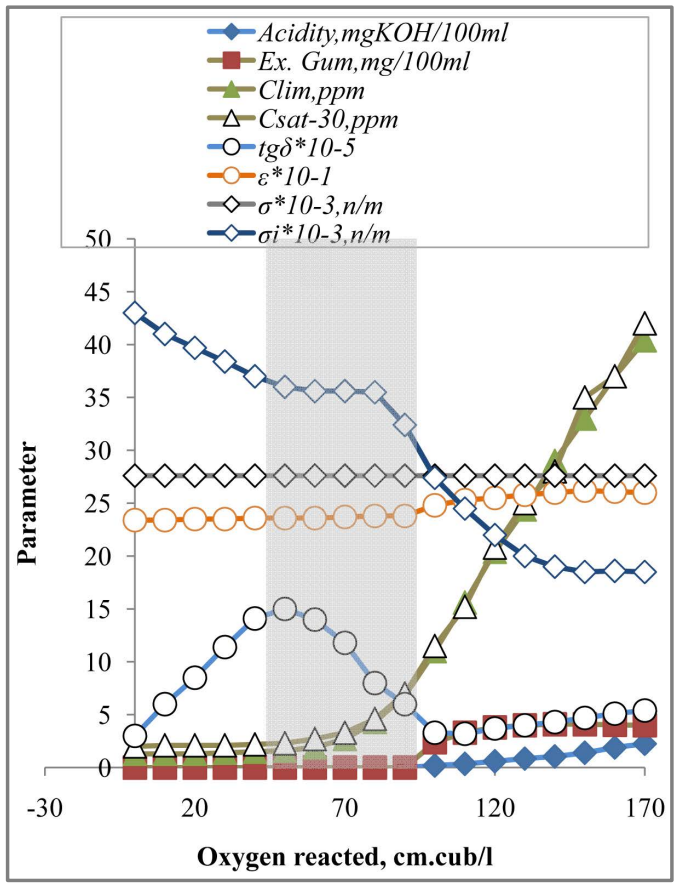

Figure 3. Physicochemical properties of kerosene versus oxidation degree.

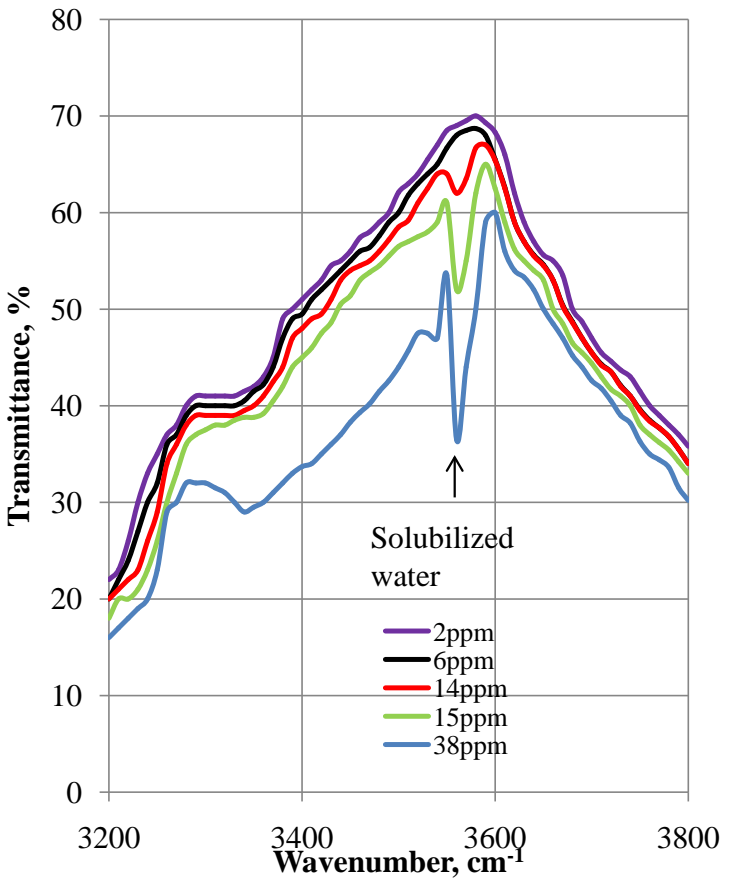

Figure 4. Kerosene Infrared Spectrum. Natural batches with acidity A $=0 ; 0.3 ; 0.5 ; 0.6$; $0.8 ; 6.2 \mathrm{mgKOH} / 100 \mathrm{ml}$.

the parameters are changed with increasing degree of fuel oxidation, except surface tension at the air-fuel boundary. The axis of the degree of oxidation can be divided into three distinct areas: the first area in the range of $0-60 \mathrm{~cm}^{3} / 1$, the second region $60-100 \mathrm{~cm}^{3} / 1$ and a third region $100-170 \mathrm{~cm}^{3} / 1$.

"Existent Gum" and "Acidity" start to grow only in the third region, have not 
been responding to oxidation before.

In the first area most severely change the interfacial tension at the water-fuel boundary $\sigma_{i}$ and dielectric loss tangent $\operatorname{tg} \delta$.

Their change indicates the appearance of the fuel polar oxygen-containing compounds. The sharp decrease in interfacial tension $\sigma_{i}$ indicates that these compounds are surfactants [7].

Judging by the nature of the parameters change (sharp bends in the second region), surfactants are in molecular, non-associated state (true solution) to a degree of oxidation of the corresponding total amount of reacted oxygen divided by the amount of fuel equal to $60 \mathrm{~cm}^{3} / 1$.

With further oxidation in a second region surfactant concentration reaches a critical micelle concentration (CMC), and fuel can be regarded as colloidal surfactant solution in a hydrocarbon liquid with all the properties inherent in particular, with the ability to solubilize, i.e. to increase the solubility of a substance through the introduction of its molecules into micelles [8].

In this case, a water solubilization in the micelles of surfactant molecules oxidation products occurs. This is confirmed by a sharp increase in the parameter "limit dryness" $C_{\lim }^{\text {dry }}$ after CMC (second region). With the increase of surfactant concentration after the CMC, the fuel has more and more water. It is not removed by vacuum drying, suggesting a possible its solubilization in micelles.

Interestingly changes in the electrical parameters. Dielectric loss tangent $\operatorname{tg} \delta$ with increasing degree of oxidation in the first region is increased more than threefold. Then there is a sharp drop to the original and further its slow growth is observed.

According to the theory of Debye, there is a dependence between $\operatorname{tg} \delta$ and concentration of polar molecules (oxidation products here) [9]:

$$
\operatorname{tg} \delta=\frac{4 \pi N_{A}}{27 k T}\left(\frac{\varepsilon+2}{\varepsilon}\right) \frac{\omega \tau}{1+\tau^{2} \omega^{2}} \mu^{2} C_{p}
$$

where $k$-Boltzmann constant;

$\varepsilon$-dielectric constant;

$\omega$-angular measurement frequency;

$\tau$-relaxation time, sec;

$T$-temperature, $K$;

$\mu$-dipole moment;

$C_{p}$-concentration of polar molecules.

Modifier $\frac{4 \pi N_{A}}{27 k T}$ at a constant temperature is constant. Changing the permitivity $\varepsilon$ not significantly affect the $\operatorname{tg} \delta$ and therefore the second factor can be considered constant also. The same can be said about the third factor, if the measurements are performed at a constant angular frequency and the position of the dispersion region (accounted for the value of $\tau=\frac{1}{\omega_{c r}}$ ) remains unchanged.

Therefore, we can write:

$$
\operatorname{tg} \delta=B \mu^{2} C_{p}
$$


where $B$-a constant factor.

Thus, in accordance with Equation (2), the oxidation of fuel in the first region surfactant concentration increases polar molecules (true solution), and as the oxidizing groups $(-\mathrm{COOH},-\mathrm{O}=\mathrm{O},-\mathrm{OH})$ do not differ much in the dipole moment $\mu$, in the area $\operatorname{tg} \delta$ increases linearly with increasing concentration. With further oxidation at a time begin to form micellar structures. Micelle formation causes a sharp reduction of the dipole moment per monomer unit attributable $\mu / n$, where $n$-number of molecules in the micelle [10]. Several times dipole moment reduction leads to a sharp $\operatorname{drop} \operatorname{tg} \delta$ (second region). With a further increase in the number of micelles and their dipole moment of consolidation virtually unchanged, and the dielectric loss tangent begins to increase again linearly with the increase of surfactant concentration (third region).

Dielectric constant $\varepsilon$ graph deviation of linearity can also be explained by the decrease attributable to the dipole moment of the monomer unit of the surfac$\tan t \mu / n$.

Figure 4 shows the results of a study of naphthenic base fuel samples, varying degrees of oxidation of a spectrometer IKS-29 in the infrared region of the spectrum.

Dissolved water in non-polar solvents has asymmetric oscillation frequency $v$ $=3705 \mathrm{~cm}^{-1}$, symmetrical $v=3614 \mathrm{~cm}^{-1}[11]$.

The content of dissolved water in the samples was $0.0006 \%-0.00015 \%$ by weight, and the band corresponding to these fluctuations is almost invisible (a slight increase in absorption at a frequency $v=3630 \mathrm{~cm}^{-1}$ ).

Absorption band $v=3550 \mathrm{~cm}^{-1}$ is most clearly expressed in the spectrum with an increasing degree of oxidation of the fuel and increasing the parameter "limit dryness" $C_{\text {lim }}^{\text {dry }}$.

The paper [12] suggested absorption band $v=3550 \mathrm{~cm}^{-1}$ belongs to a bound water molecules in nonpolar organic solvents.

The relationship of the absorption band $v=3550 \mathrm{~cm}^{-1}$ intensity with a "limit dryness" $C_{\lim }^{\text {dry }}$ parameter indicates its attachment to a bound (solubilized) water inside the reverse micelles of surfactants products from liquid phase oxidation.

\section{Conclusion}

The studies showed a significant effect of natural surfactants contained in the hydrocarbon fuel on water solubility. The possibility of micellar colloidal structures forming in hydrocarbon fuels with increasing concentrations of natural surfactant-oxidation products was determined. The increase in water solubility can result from solubilization of the water molecules inside reverse micelles formed by the oxidation products of hydrocarbon fuels. This process can affect on undissolved water content in aircraft fuel systems.

\section{Acknowledgements}

The authors would like to thank Airbus colleagues for technical discussion of 
water/fuel problems.

\section{References}

[1] (2004) Handbook of Aviation Fuel Properties. Technical Report, CRC Report No. 635, 3rd Edition, Coordinating Research Council, SAE.

[2] Zherebtsov, V. and Peganova, M. (2012) Water Solubility versus Temperature in Jet Aviation Fuel. Fuel, 102, 831-834.

[3] Baena, S., Repetto, S., Lawson, C. and Lam, J.K.-W. (2013) Behaviour of Water in Jet Fuel-A Literature Review. Progress in Aerospace Sciences, 60, 35-44.

[4] Lam, J., Carpenter, M., Williams, C. and Hetherington, J. (2014) Water Solubility Characteristics of Current Aviation Jet Fuels. Fuel, 133, 26-33.

[5] Hemighaus, G., Boval, T., Bacha, J., Barnes, F., Franklin, M., Gibbs, L., Hogue, N., Jones, J., Lesnini, D., Lind, J. and Morris, J. (2006) Aviation Fuels Technical Review, Technical Report. Chevron Corporation.

[6] Merkulov, O., Zherebtsov, V., Peganova, M., Kitanin, E., et al. (2011) OBIGGS for Fuel System Water Management-Proof of Concept. SAE International Journal of Aerospace, 4, 1465-1474. https://doi.org/10.4271/2011-01-2793

[7] Arne, T. (2014) Micelle Formation, MPI of Colloids and Interfaces. Golm.

[8] Abuin, E., Lissi, E., Duarte, R., Silber, J.J. and Biasutti, M.A. (2002) Solubilization in AOT-Water Reverse Micelles. Effect of the External Solvent. Langmuir, 18, 83408344. https://doi.org/10.1021/la020492o

[9] Oehme, F. (1958) Dielektrische Meßmethoden zur quantitativen Analyse und für chemische Strukturbestimmungen. Verlag Chemie. Weinheim/Bergstr.

[10] Eicke, H.F. and Christen, H. (1974) On the Stability of Micelles in Apolar Media. Journal of Colloid and Interface Science, 46, 417-427.

[11] Abramson, A.A. (1975) Surfactant Compounds. Chemistry, Leningrad.

[12] Karyakina, A.V. and Kriventsova, G.L. (1973) The Statement of Water in Organic and Nonorganic Solvents. Science, Moscow.

Submit or recommend next manuscript to OALib Journal and we will provide best service for you:

- Publication frequency: Monthly

- 9 subject areas of science, technology and medicine

- Fair and rigorous peer-review system

- Fast publication process

- Article promotion in various social networking sites (LinkedIn, Facebook, Twitter, etc.)

- Maximum dissemination of your research work

Submit Your Paper Online: Click Here to Submit

Or Contact service@oalib.com 